\title{
МИСТЕЦТВОЗНАВСТВО
}

\author{
DOI: https://doi.org/10.32839/2304-5809/2020-12-88-70 \\ УДК 37.016:796.012.62]:793.3
}

Драч Т.Л.

Національна академія керівних кадрів культури та мистецтв; Студія танцю «Шоколад», м. Львів

\section{СТРЕТЧІНГ ЯК ВАЖЛИВИЙ КОМПОНЕНТ ПІДГОТОВКИ В ТАНЦІ-МОДЕРН}

\begin{abstract}
Анотація. Стретчінг - популярний наразі вид занять, який пропонують танцювальні студії, стретчінг може бути спрямований на розвиток професіоналів, де головним показником результативності будуть «шпагати з запасом», та "подвійна складка» на гнучкість. А може бути більш лояльною, спрямованою на розвиток фізичних якостей організму, підготовки до виконання танцювальних напрямків та містити в собі елементи суглобової гімнастики. Саме такий стретчінг ми пропонуемо на наших заняттях, у якості підготовки до виконання танцю-модерн. Метою нашого дослідження стало дослідити особливості стретчінгу та фрізичної підготовки танцівника у танці модерн, а завданнями: проаналізувати попередні праці у цьому напрямку; вивчити рухи, що можливо застосовувати під час розігріву та підготовки виконавців; розробити урок зі стретчінгу, який спрямований на підготовку до виконання технік Марти Грехем. В ході дослідження ми розробили власний варіант проведення уроку зі стретчінгу, який спрямований на розвиток гнучкості, пластичності та фрізичної досконалості танцівника, який дозволить добре підготуватися до майбутніх сучасних балетних вистав.
\end{abstract}

Ключові слова: стретчінг, танець-модерн, аматори, методика виконання, техніки Марти Грехем.

Drach Tamara National Academy of Managerial Staff of Culture and Art; Dance Studio "Chokolate"

\section{STRETCHING AS IMPORTANT PART OF PREPARATION IN MODERN-DANCE}

Summary. Stretching is a popular type of training offered by dance studios, stretching can be aimed to the development of professionals, and can be more loyal, aimed at developing the physical qualities of the body, preparation for dance activities and contain elements of gymnastics. This is exactly the kind of stretching we offer in our classes, in preparation for the performance of modern dance. The aim of our research was to consider the features of stretching and physical training of dancers in modern dance, and tasks: to analyze previous works in the direction of training amateur performers in modern dance; to study and analyze the movements that can be used during warm-up and preliminary training for performers of modern dance; to develop a stretching methods, which are aimed to train amateur performers in the direction of modern-choreography, for the techniques of Martha Graham. Methods of research. In the process of research such scientific methods as analysis of specialized literature, pedagogical experiment, analysis of video and photo materials were used. These methods helped us to solve the problem and made experimentally confirmed conclusions from this research. Novelty. Stretching as an important element of a dancer's development is often used in the process of training performers in absolutely all areas of dance art. Modern choreography is not exception, good stretching is necessary. Therefore, we decided to explore the available methodological and practical materials on the application for stretching in the training of modern dancers. Previously, the question of using stretching in the process of preparing dancers has not considered, as well as the main features of stretching for amateurs who practice modern choreography. Conclusions. Thus, in the course of the experimental research, we were able to analyze already written training programs in modern dance, we studied the possible options for stretching, both in pairs and individually, which will help as for professionals as well as for amateurs preparation for performing techniques by Martha Graham. We also developed our own version of the stretching lesson, which aims to develop the flexibility, plasticity and physical perfection of the dancer, which will prepare well for future modern ballet performances.

Keywords: stretching, modern-dance, amateurs, methods of performing, techniques of Martha Graham.

Постановка наукової проблеми та їі значення. Хореографрія модерн вимагає від виконавця хорошої фрізичної підготовки та фрізичних даних. Важливо зрозуміти, яким чином підготувати тіло танщівника до виконання танцювальних номерів у стилі модерн. На даний час система підготовки в танці-модерн є дуже різноманітною, однак хороший «крок» та виворотність, дотягнуті стопи та гнучкість є незмінною складовою професійного виконання, тож ми вирішили з'ясувати для себе, яким чином слід розтягувати танцівника для виконання хореографії модерн та чи $є$ особливості у підготовці до цього напрямку.
Аналіз досліджень цієї проблеми. 3 цієї теми, що розглядаеться, висвітлює підготовку в танці - модерн праці Нікітіна В.Ю. (2000), Мартинюк О.В. (2019), Акімової С.В. (2014), Шарікова Д.І. (2010) та ін. Кожний з цих авторів по своєму розглядає підготовку та розігрів в процесі виконання танцю-модерн, адже кожний автор аналізуе різні методики та техніки цього напрямку. Для нас стала цікавою точка зору кожного 3 них, адже для створення загальної картини у підготовці аматорів у танці-модерн слід розуміти, на які саме аспекти підготовки слід звернути особливу увагу. 
Виділення невирішених раніше частин загальної проблеми. Стретчінг як важливий елемент розвитку танцівника часто зустрічається в процесі підготовки виконавців абсолютно всіх напрямків танцювального мистецтва, не виключенням $е$ i хореографія модерн, де вагому роль відіграють рухи, де необхідна хороша розтяжка. Тож, ми вирішили дослідити наявні методичні та практичні матеріали щодо застосування стретчінгу в процесі підготовки сучасних танцівників. Раніше ще не розглядалося питання доцільності розтяжок в процесі підготовки танцівників до виконання танцюмодерн, а також основні особливості стретчінгу для аматорів, які практикують сучасні напрямки хореографіï.

Мета і завдання статті. Тож для висвітлення даної тематики та обгрунтування ï актуальності, ми поставили таку мету: дослідити особливості стретчінгу та фізичної підготовки танцівника у танщі - модерн.

Цій меті були підпорядковані такі завдання:

- проаналізувати попередні праці у напрямку підготовки виконавців-аматорів у танцімодерн;

- вивчити та проаналізувати рухи, що можливо застосовувати під час розігріву та попередньої підготовки для виконавців танцю-модерн;

- розробити урок зі стретчінгу, який спрямований на підготовку виконавців-аматорів у напрямку стилю модерн, для технік Марти Грехем.

Виклад основного матеріалу дослідження. Хореографрія, як сучасна, так i класична вимагає від виконавця ретельної попередньої підготовки, яка дозволить виконувати ті па, які характерні для певного стилю танцю. Особливого розвитку наразі набув стиль модерн в хореоградрічному мистецтві, де окрім roll up, roll down, twist, back flat, Зустрічаються рухи, в яких виконавцям необхідно мати добре розвинутий крок, гнучкість та пластичність. Саме тому актуальним є питання стретчінгу для танщівників танцю-модерн. На нашу думку, цей стиль хореографiї, можна розглядати, як один з найбільш адаптованих для аматорів, людей, які раніше не практикували танщі, і почали займатися вже у дорослому віці [2, с. 16].

В техніках Марти Грехем ми бачимо використання contraction та release, які не тільки додають пластичної виразності виконавцю, але й сприяють хорошому оздоровчому ефекту для організму, виконання deep body bend, позитивно впливає на розвиток м'язової системи та розтяжки, тому під час занять зі стретчінгу актуальним може бути виконання рухів у партері, які допоможуть покращити розтяжки. Наразі ми часто звертаємо увагу, що для сучасного танцівника крок на 180 градусів, вже стає нормою. Але чи дійсно потрібний такий підйом ніг під час виконання танцю-модерн, чи інших стилів хореограdiï - це питання спірне.

Однак для розвитку гнучкості та розтяжки, ми можемо застосовувати техніки танцю-модерн, адже вони допоможуть виконавцю здобути правильні та граційні форми, яка врешті-решт, дозволить досягнути потрібного результату. Бажання покращити «крок» $е$ актуальним для су- часного танцівника, але робити це потрібно поступово та зважати на особливості тіло будови, для того, щоб по можливості не зашкодити собі. В такому випадку ми пропонуемо розтягуватися більш лояльним чином, найліпше, в парах, адже виконавці відчувають свій біль і відповідно розуміють, яким чином слід розтягувати інших [5, с. 67].

Розтягування, на нашу думку має стати своєрідною суглобовою гімнастикою, де виконавець може не тільки покращити свій крок, але й позитивно вплинути на стан свого організму. Виконання вправ у партері сприяе позитивному впливу на весь організм, а робота в парах дозволить цікавіше проводити заняття, а отже, i швидше робити успіхи.

Актуальною може стати партерна гімнастика на підлозі, де ми для початку, виконуемо екзерсис, який складається 3 plie, battement tendu, ronds, battement fondu, grand battements та інші. Ці вправи ми виконуемо на спині, на животі, та на боку, варіюючи різні танцювальні комбінації [1, с. 55].

Обов'язково розробляемо крок вперед, вбік та назад, а ще допомагаємо один одному у розвитку «складочки» та гнучкості спини. Ці вправи в подальшому дозволять сформувати у танщівника правильне виконання вправ у партері в танцімодерн.

Танець-модерн грунтуеться на техніках Марти Грехем, Рут Сен-Дені, Теда Шоуна та ін. Завдяки виконанню вправ у стилі модерн ми можемо розвинути гнучкість, покращити самопочуття, оздоровити організм людини. Тож, доцільним стає дослідження впливу танцю-модерн на розвиток гнучкості людини, iї пластичності. А також, навпаки, наскільки важлива хороша розтяжка для виконання технік танцю-модерн та у виконавській майстерності [3, с. 45].

Ми робимо скручування тіла twist в парах, що допомагае у розвитку гнучкості суглобів. Twist виконуеться у двох варіантах, у frog-position, та в партері - з рівними ногами. При нахилі тулуба, партнеру слід контролювати рівне положення спини.

Stretch важливий та необхідний елемент розтяжок в танці-модерн, адже дотягнутість стопи та правильнее ії положення - це показник професійності виконавця. Саме тому ми продовжуемо виконувати вправи у партері - робимо stretch стопи, як у положенні pointe, так і в положенні flex, що дозволяе розвинути нам максимальну амплітуду в русі стопи та її гнучкість у всіх напрямках [див. фото 2].

Важливо усвідомлювати, що в танцювальні студії приходять люди різного віку та рівня підготовки і для того, що підготувати їх до виконання елементів танцю-модерн слід ретельно підготувати їх тіло. Багатьом з них важко дається так звана "канапка", через зміщення хребців в спині, або, наприклад, постійної сидячої роботи [див. фото 3]. Відповідно з ними суглобова гімнастика - стретчінг, має бути лояльнішим та поступовим. Вимагати від них відразу виконати deep body bend або лягти в "канапку» може бути небезпечно. Тому розробляються спеціальні вправи для витягування хребта, коли партнер тягне свого підопічного за руки, а той 


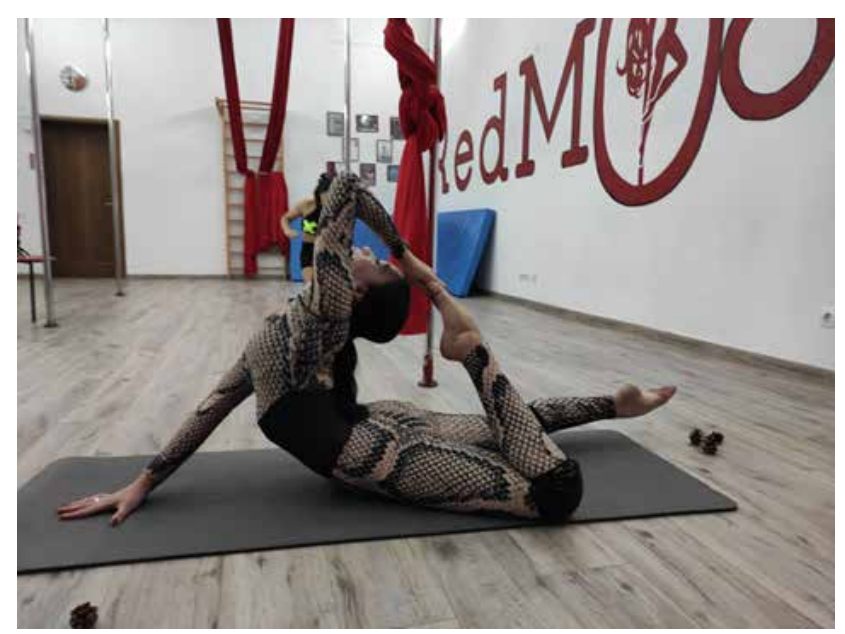

Фото 1. Виконання вправи на розвиток гнучкості спини

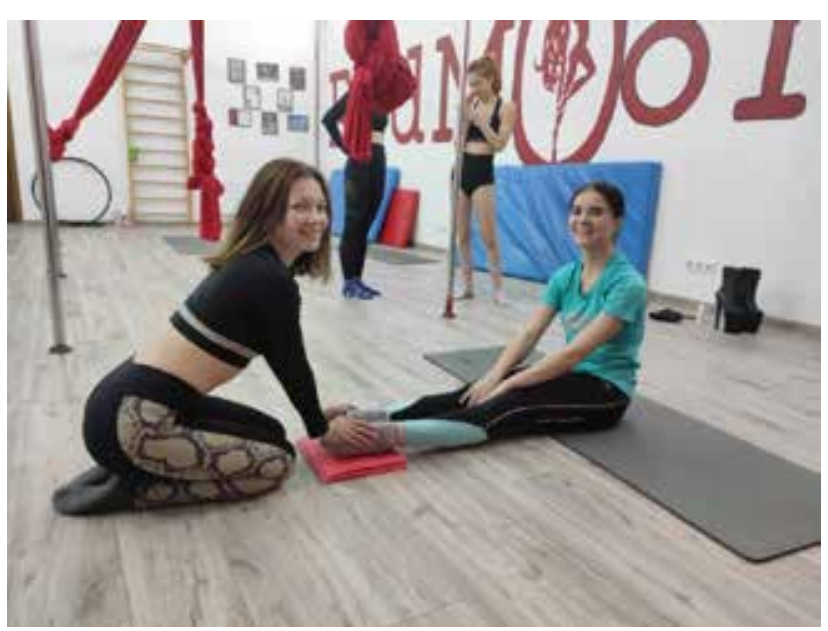

Фото 2. Stretch стопи, pointe

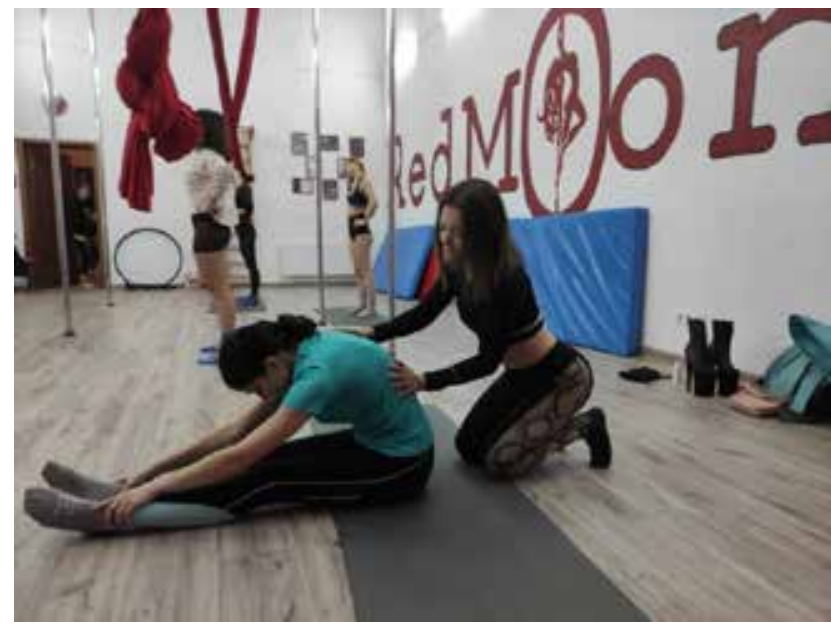

Фото 3. Виконання «складочки». Робота в парі зад. Таким чином, варто приділити цьому увагу на занятті зі стретчінгу. Так само ми можемо робити це в парах: тягнемо ногу вперед, притримуємо опорну ногу та тягнемо робочу. При розтяжках вбік ми обов'язково фріксуємо бедро та сідниці, щоб при підйомі ноги не дозволяти піднімати сідниці разом 3 ногою, що є академічно не вірним виконанням. Під час розвитку кроку назад, важливо притримувати бедро, для того, щоб нога піднімалася окремо та щоб ми не підключалися сідниці $[4$, с. 8].

Під час виконання lay out назад - це так само актуально, адже нога має підніматися вище за бедро, тоді лінії пози виходять довгими, а виконання руху більш гармонійним.

Окрім того, під час занять стретчінгол, варто приділити увагу і розвитку гнучкості спини, адже здоровий та гнучкий хребет дозволяє виконувати вправи 3 особливою легкістю, та робити чудові twist в корпусі.

Ми можемо пов'язувати вправи на розвиток гнучкості спини 3 вправами на розтяжки м'язів рук, що буде особливо актуальним під час виконання adajio у стилі модерн, в залежності від завдань хореографа, дозволяе розвинути максимальну амплітуду рук та спини [див. фрото 1]. Можливо виконання розтяжки на гнучкість спини в парах. Ми можемо допомагати партнеру у виконанні roll назад, тримаючи його за руки, а також допомагаючи йому піднімати назад обидві ноги, що суттево знімає навантаження $з$ попереку. Окрім того, для ліпшого розвитку м'язів ми пропонуємо виконавцям тонізуючий масаж валіком наприкінці заняття, який допомагає зняти навантаження 3 м'язів та надати тонізуючого ефекту для покращення загального стану організму. Вправа дуже корисна адже дозволяе зробити заняття зі стретчінгу приемним відпочинком після робочого дня та надати відповідного стану м'язам під виконання collapse у танці-модерн.

Висновки та перспективи подальшого дослідження. Таким чином, в ході проведеного експериментального дослідження, ми зуміли проаналізувати вже написані програми підготовки у танці-модерн, ми вивчили можливі варіанти розтяжок, як в парі, так і індивідуальні, котрі допоможуть продесійно та 3 користю для здоров'я організму, підготувати танцівника для виконання технік Марти Грехем. А також розробили власний варіант проведення уроку зі стретчінгу, який спрямований на розвиток гнучкості, пластичності та фрізичної досконалості танцівника, який дозволить добре підготуватися до майбутніх сучасних балетних вистав. 


\section{Список літератури:}

1. Акімова С.В. Вправи класичного екзерсису та партерного тренажу у фізичному вихованні дошкільників. Сучасні проблеми розвитку теорії та методики гімнастики та хореограббї : збірник наук. матеріалів. 2014. Вип. 13. С. 56-61.

2. Никитин В.Ю. Модерн-джаз танец: История. Методика. Практика. Москва : Изд-во ГИТИС, 2000.440 с.

3. Чілікіна Н.О. Тілесні практики в сучасній хореографрічній культурі [Текст] : авторедр. дис. канд. мистецтвознавства: 26.00.01, Харків. держ. акад. культури. Харків, 2014. 20 с.

4. Шариков Д.І. Теорія, історія та практика сучасної хореографії: генезис і класифікація сучасної хореографрїнапрями, стилі, види [Текст] : монографія. Київський міжнародний університет, Інститут телебачення, кіно і театру, Каф. Театрального мистецтва. Київ : КиМУ, 2010. С. 185-198.

5. Шариков Д.I. "Contemporary dance" у балетмейстерському мистецтві [Текст] : навч. посіб. Київ. міжнародний університет, Ін-т телебачення, кіно і театру, кафедра театр. мистецтва. Київ : КиМУ, 2010. 173 с.

\section{References:}

1. Akimova S.V. (2014) Vpravy klasichnogo exzersisymta parternogo trenaju u fizychnomu vyhovanni doshkilnikiv [The exercises of classical dance and parter training in physical training of preschool children]. Modern problem of development of the Theory and methodology of gymnastics and choreography: collection of scientific material. Vol. XIII, pp. 56-61.

2. Nikitin V.U. (2000) Modern-jazz tanec: Istorija. Metodika. Practika [Modern-jazz dance: History. Methodology. Practice]. Moskow: Editional house "SIT\&S", 440 p.

3. Chilikina N.O. (2014) Tilesni practiky u suchasniy choreographichniy culture [Body methods in modern choreographic culture] [Text]: dissertation abstract of candidate of art history: 26.00.01, Charkiv state academy of culture. Charkiv, $20 \mathrm{p}$.

4. Sharikov D.I. (2010) Teorija, istorija ta practyka suchasnoyi choreography: genesis i klasifikacija suchasnoji choreography - napryamy, styli, vydy [Theory, history and practice of modern choreography: genesis and classification of modern choreography - branches, styles, kinds] [Text]: monography. Kyiv National University, Institute of television, cinema and theatre, Departnent of theatre art. Kyiv: K\&AU, pp. 185-198.

5. Sharikov D.I. (2010) "Contemporary dance" u baletmeysterskomu mystetstvi. ["Contemporary dance" in the balletmaster's art] [Text]: tutorial. Kyiv International University, Institute of television, cinema and theatre, department of theatrical art. Kyiv: K\&AU, $173 \mathrm{p}$. 